\title{
Analysing Secondary infections of Coronavirus Disease 2019 Across the Geopolitical Zones of Nigeria Using Estimated Rt
}

\author{
Bibi Umar Muhammed ${ }^{* 1}$, Saad Aliyu Ahmed ${ }^{2,3}$, Idris M. Jega ${ }^{4}$ \\ ${ }^{1}$ Department of Geography, Federal University of Kashere, PMB 0182 Gombe, Nigeria \\ ${ }^{2}$ Department of Pathology, Ahmadu Bello University Zaria, 810001 Nigeria \\ ${ }^{3}$ Federal Medical Centre, Abuja - Nigeria. \\ ${ }^{4}$ Department of Strategic Space Applications, National Space Research Development Agency (NASRDA) Airport \\ Road Abuja, Nigeria \\ "Corresponding author email: bibi.muhammed@gmail.com
}

Article history

\begin{tabular}{llll} 
Received & Received in revised form & Accepted & Available online \\
30 July 2020 & 21 August 2020 & 31 August 2020 & 31 August 2020 \\
\hline
\end{tabular}

Abstract: Time dependent reproduction number (represented as TD $-\mathrm{R}_{0}$ ) is a measure of secondary infections or transmissibility of a disease useful in monitoring changes in the rate of infection and assessing policies put in place to control the spread of a disease. In this study, we used daily infections situation report of COVID - 19 were published by the Nigeria Centre for Disease Control (NCDC) to estimate Nigeria's TD - $\mathrm{R}_{0}$ then repeated the same method for the six geo - political zones in the country. Estimates of TD $-\mathrm{R}_{0}$ values for the country from the $23^{\text {rd }}$ of March $-27^{\text {th }}$ of May 2020 fluctuated with a maximum of $2.3(95 \% \mathrm{CrI})$ on the $19^{\text {th }}$ of April and a minimum of 0.83 (95\% CrI) on the $16^{\text {th }}$ May 2020. Despite the decline in TD $-\mathrm{R}_{0}$ since the early stages of the outbreak of COVID 19 in Nigeria, suggesting a fall in the expected rate of secondary infection, apart from the northwest and the northeast geo - political zones values remain above 1.0 for other zones and the country, generally. The Kolmogorov - Smirnov (KS) test was used to test the null hypothesis stating that the means of TD - $\mathrm{R}_{0}$ across the geo-political zones does not follow the same distribution pattern. After making adjustments for Type 1 - error, we accepted the null hypothesis ( $\mathrm{p}<0.05$ ) for six pairs of geo-political zones. We conclude that our findings are significant in studying the COVID - 19 epidemic in Nigeria and important in evaluating the strategies deployed by governments at the national and regional levels, thus, the same method can be replicated across Africa.

Keywords: COVID - 19, pandemic, time dependent reproduction number, Nigeria, Geo-political zones

\section{Introduction}

The novel Coronavirus Disease 2019 is a strain of influenza related to the severe acute respiratory syndrome (SARS) officially named by the World Health Organisation (WHO) as COVID - 19 [1]. An outbreak of the disease was first reported in the city of Wuhan, China on the $29^{\text {th }}$ of December 2019 [1] and by the $11^{\text {th }}$ of March 2020 it was declared a pandemic by WHO [2]. Many countries in the world were unprepared for a pandemic of such magnitude coupled with little knowledge about the disease. Therefore, the only early intervention strategies that governments can adopt to mitigate the spread of the disease is to delay the peak of the infection (popularly referred as "flattening the curve") in order to prevent the health system from being overwhelmed and have time for the development of an anti - virus treatment and a vaccine [3].

In Nigeria Covid - 19 infections were first brought into the country by returning citizens and foreign nationals coming from countries where the number of infections had already reached levels of epidemics. The country reported its first index case of COVID - 19 on the $27^{\text {th }}$ of February, 2020 [4]. A number of preventive and mitigation strategies were adopted before and after the first index case coordinated by the Nigeria Centre for Disease Control - NCDC [5] in conjunction with the Presidential Task Force (PTA) on COVID - 19. These include mass sensitization programs on COVID - 19, the deployment of thermal scanning devices at the major ports of entry into the country and two weeks self isolation for people arriving into the country as preventive measures, then followed by closure of the country's national and interstate borders, stay at home advisory, closing of public facilities and total lockdown of areas with high infections as mitigation measures.

Considering the impact of the mitigation measures are adopted in the country on the control of the spread of COVID - 19 and the livelihoods of the general population it is necessary to monitor and evaluate the progress made in the implementation of such strategies both at national and regional levels. Among several proxies are used in monitoring the progress of a disease during outbreaks is the time dependent reproduction number TD $-\mathrm{R}_{0}$ [6]. The basic reproduction number $\mathrm{R}_{0}$ is the average number of secondary infections resulting from a single primary infection (Cori et al., 2013) over the course 
of an outbreak. However, TD $-\mathrm{R}_{0}$ is time bound and a measure of the expected number of secondary infections from a primary infection at time t [7]. It is a measure of the transmissibility of a disease. In the course of an outbreak the values of $\mathrm{TD}-\mathrm{R}_{0}$ changes varying with the reported cases of infection. A TD $\mathrm{R}_{0}$ value of 2.0 suggest that two secondary cases of infection are expected from a single primary case. When the value of $T D-R_{0}$ falls to below 1.0 , it is expected that the number of secondary cases of infection will gradually disappear.

It is useful for assessing the success of intervention measures put in place during an outbreak of a disease. Apart from that $\mathrm{TD}-\mathrm{R}_{0}$ is also useful for monitoring trends during an epidemic, the identification of "super spreader events" and a parameter for epidemic/ disease outbreak are related mathematical models [6]. Musa et al. [8] estimated the basic and exponential reproduction number of COVID - 19 for the African continent. Apart from the work of Adegboye et al. [9] and Adekunle et al. [10] that attempted to estimate $\mathrm{TD}-\mathrm{R}_{0}$ for the country during the early stages of the pandemic to the best of our knowledge, there is no effort has been made to further estimate TD $-\mathrm{R}_{0}$ as the epidemic progressed. In this study, we intended to further this method by estimating TD $-\mathrm{R}_{0}$ over a longer period when the outbreak is well established in the country, reduce the error margins in the estimate and also estimate $\mathrm{TD}-\mathrm{R}_{0}$ across the six geo-political in the country. We attempted to test a null hypothesis stating "that the estimated $\mathrm{TD}-\mathrm{R}_{0}$ between geo political zones do not follow the same pattern", and if it is true will suggest heterogeneity among the zones and a more specific intervention approach which is required for each zone to control COVID - 19.

The following section describe the geographical characteristics of the study area, the data and analysis method used (materials and method section). We present our findings in the result section. This is followed by the discussions and conclusion, that made based on the findings presented in the discussion and conclusion sections.

\section{Materials and Methods}

The study developed a research design (see Figure 1) that is aimed at achieving the set objectives which is to estimate TD_R0 for Nigeria and the six geopolitical zones in the country and also determine the difference/similarities in the pattern of secondary infections across the geo - political zones in the country. Sources of the daily Covid - 19 infection report used in estimating TD-R0, analysis methods and a brief description of the study area are further explained in this section.

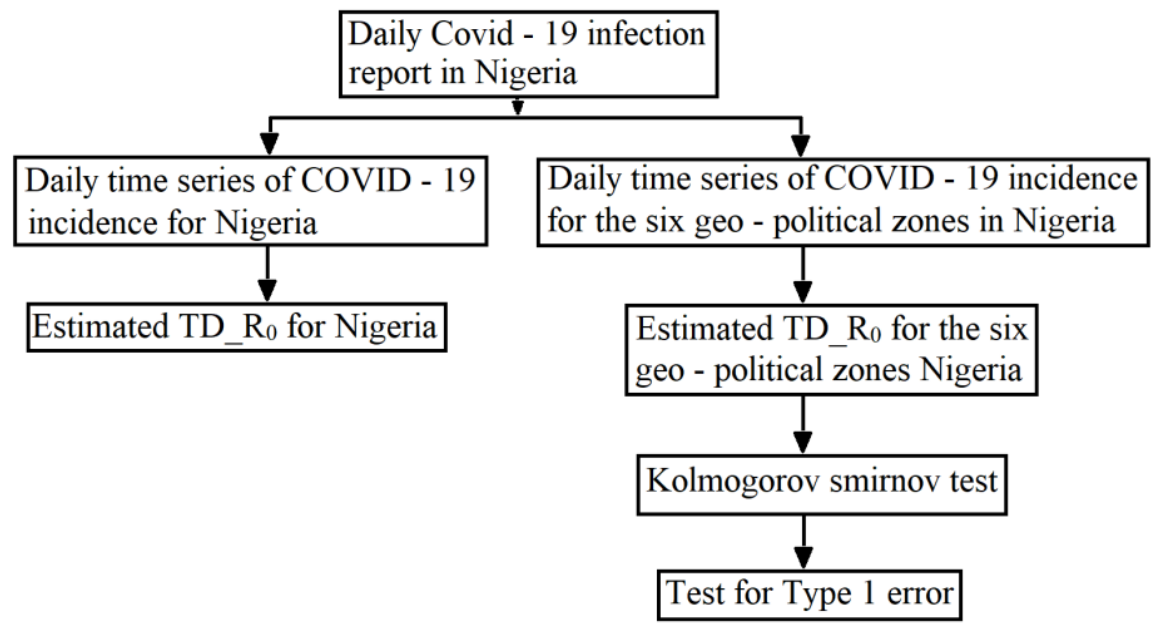

Figure 1: Research flow chart

\subsection{The Study Area}

Nigeria with an estimated population of 206 million [11] is the most populous country in Africa. It is located in West Africa and lies between latitude $4^{\mathrm{O}}-14^{\mathrm{O}}$ north of the Equator and longitude $3^{\mathrm{O}}-15^{\mathrm{O}}$ east of the Greenwich meridian line. The country comprises of 36 states and the Federal Capital Territory (FCT) Abuja are often grouped into six geo - political zones (see Figure 2 and Table 1). 


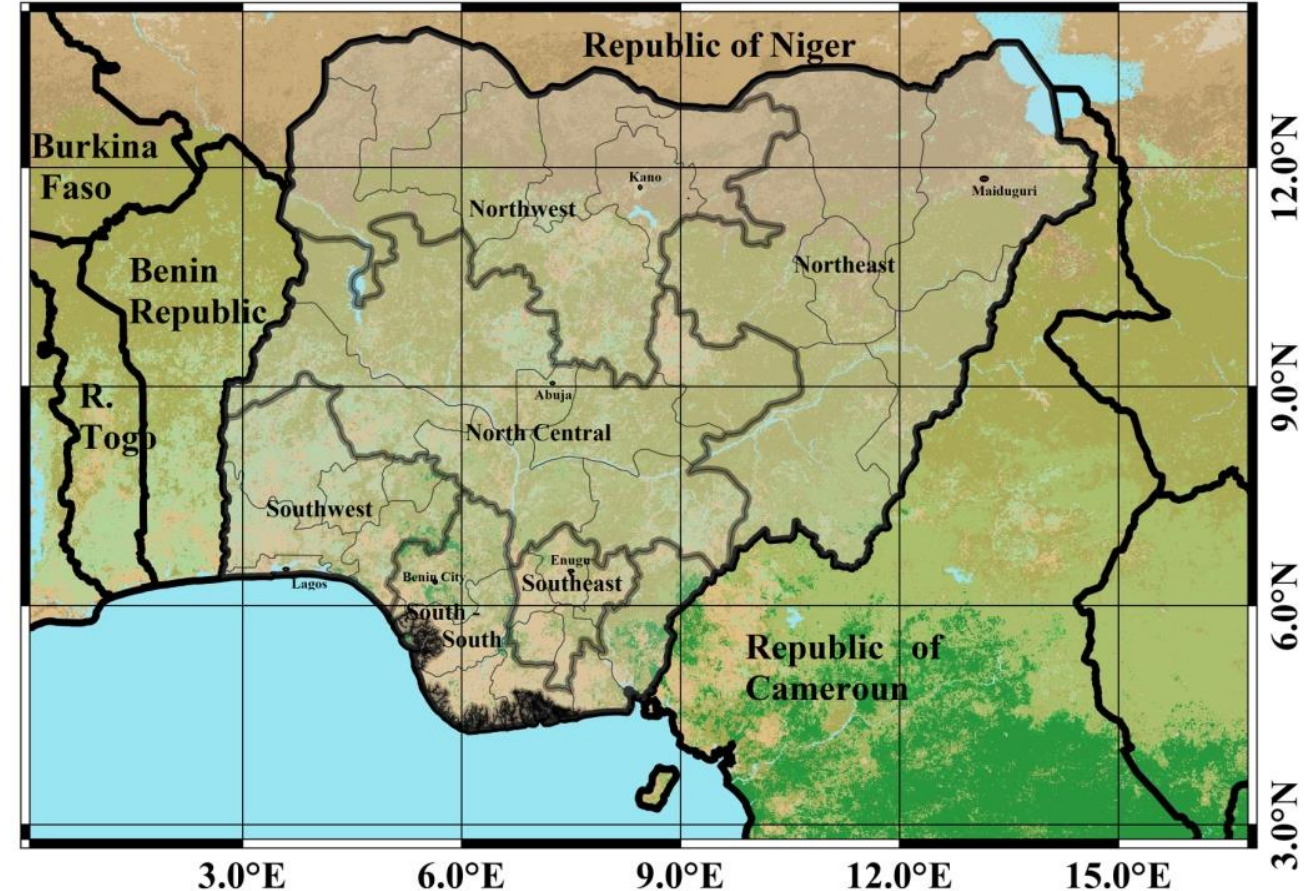

Figure 2: Map of Nigeria showing the six geo - political zones

Table 1. The Six geo - political zones in Nigeria comprising of 36 states and the Federal Capital Territory (FCT) Abuja

\begin{tabular}{cll}
\hline S/No. & \multicolumn{1}{c}{ Geo - political zones } & \multicolumn{1}{c}{ States } \\
\hline 1 & North Central & Benue, Kogi, Kwara, Nasarawa, Niger, Plateau, FCT \\
2 & Northeast & Adamawa, Bauchi, Borno, Gombe, Taraba, Yobe \\
3 & Northwest & Jigawa, Kaduna, Kano, Katsina, Kebbi, Sokoto, Zamfara \\
4 & South West & Ekiti, Lagos, Ogun, Ondo, Osun, Oyo \\
5 & Southeast & Abia, Anambra, Ebonyi, Enugu, Imo \\
6 & South - South & Akwa Ibom, Bayelsa, Cross River, Delta, Edo, Rivers \\
\hline
\end{tabular}

\subsection{Sources of data}

In estimating $\mathrm{TD}-\mathrm{R}_{0}$, we used the daily COVID - 19 infections situation report in Nigeria numbers $01-89$ from the $28^{\text {th }}$ of February to $27^{\text {th }}$ of May 2020 downloaded from the country's Nigeria Centre for Disease Control (NCDC) website (https://ncdc.gov.ng/diseases/sitreps/?cat=14\&name= An\%20update\%20of\%20COVID-

19\%20outbreak\%20in\%20Nigeria ). The NCDC daily COVID - 19 infection data for the whole country comprises of daily infection data for each of the 36 states in the country and the Federal Capital Territory (FCT) Abuja. In some reports are also contained the daily data on the number of people screened for the virus, those discharged from COVID - 19 care centers across the country and the deceased.

\subsection{Data Analysis Techniques}

We used EpiEstim package installed on $\mathrm{R}$ version 3.6.1 to estimate $\mathrm{TD}-\mathrm{R}_{0}$. EpiEstim uses time series data of infections to create a distribution of the serial interval - SI (time between the manifestation of symptoms from a primary case and that of a secondary case) and estimate $\mathrm{TD}-\mathrm{R}_{0}$. The method was first developed by Cori et al. (2013) and further modified by Thompson et al. (2019) to include imported and local incidence of a disease. The method assumes that the first incidence of a disease is imported and can incorporate several of such cases in the time series. The method was chosen for this study because of its simplicity of use and the ability to incorporate a single data set (time series of infections) in making estimates of TD $-\mathrm{R}_{0}$. Several studies $[7,9,10,12-14]$ have also applied this method in estimating TD - R0, studying the spread of a disease and evaluation of intervention strategies. In order to minimize errors, in initial estimates of TD $\mathrm{R}_{0}$, we skipped the first few reported incidences characterized by gaps in the data and wide time intervals between reported cases which is naturally 
the period between the first reported case and a full outbreak of the disease. A conservative mean SI of 4.8 days and standard deviation of 2.3 days were adopted from Nishiura et al. [15] in making the TD $\mathrm{R}_{0}$ estimates.

In the $\mathrm{R}$ software platform the Kolomogorov Smirnov (KS) test was used to test for regional differences pair wise in order to test for the null

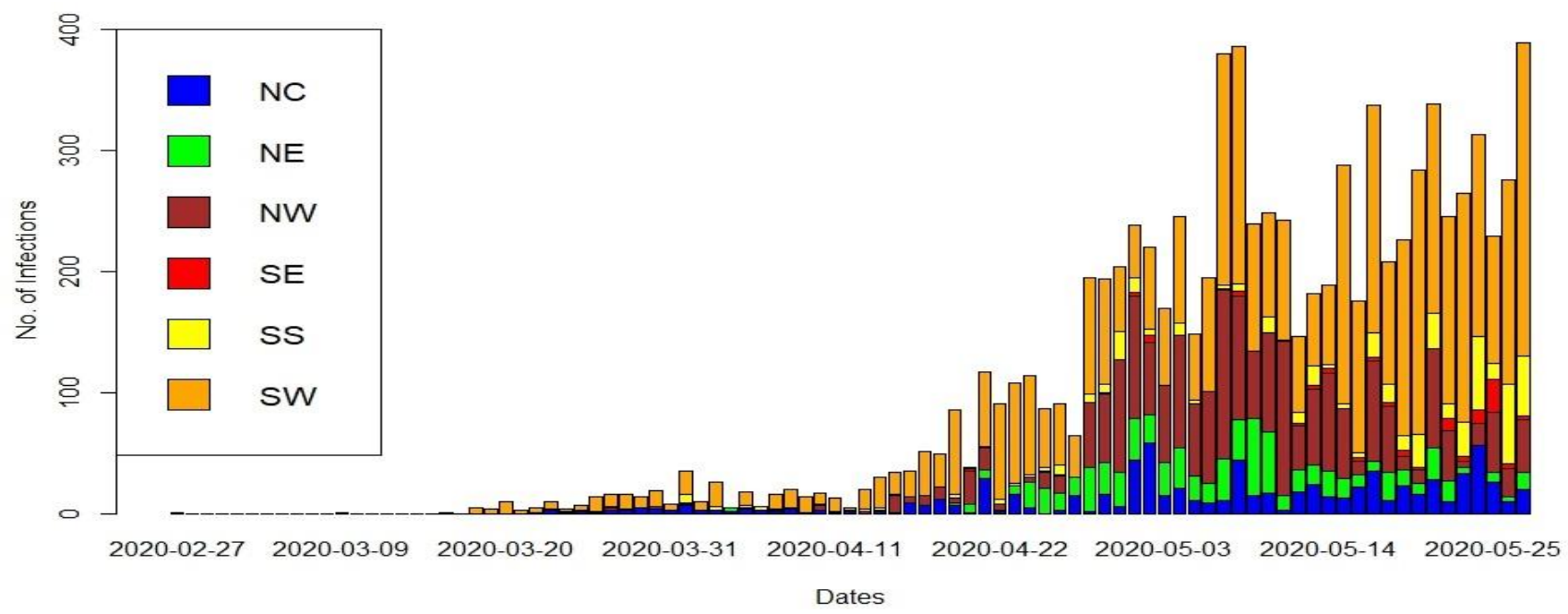

Figure 3. Daily infection of COVD -19 in Nigeria and the six geo - political zones from $27^{\text {th }}$ of February $2020-27^{\text {th }}$ May 2020

*Note: NC - North central, NE - Northeast, NW - Northwest, SE - Southeast, SS - South south and SW - Southwest

\section{Results}

Like other studies such as $\mathrm{Hu}$ [13] and Adekunle et al. [10], we assume that all cases of COVID - 19 infections in the country are reported for our results to qualify as a true reflection of trends in the country. The total number of COVID - 19 infections in Nigeria from the $27^{\text {th }}$ of February 2020 to the $27^{\text {th }}$ of May 2020 was collated from the NCDC infections situation report for the period and is hypothesis "that the estimated $\mathrm{TD}-\mathrm{R}_{0}$ between geopolitical zones do not follow the same distribution pattern". P - values of the KS test were adjusted for Type 1 error using the Bonferroni, Holm [16], Hochberg [17], Hommel [18], Benjamini and Hochberg [19] and Benjamini and Yekutieli [20] tests. presented in Figure 3 showing the contribution of each geo - political zone. The total number of COVID - 19 infections in the country stands at 8,735 with the southwest geo - political zone having the highest number of infections (52.7\%) followed by the northwest (22.6\%) and the north central (9.2\%), respectively. COVID - 19 infections from the other 3 geo - political zones (northeast, southeast and south south) form only $15.5 \%$ of recorded cases during the period under study.

Table 2: Summary table of important dates used in estimating TD $-\mathrm{R}_{0}$

\begin{tabular}{|c|c|c|c|c|}
\hline \multirow[t]{2}{*}{ Place } & \multirow{2}{*}{$\begin{array}{l}\text { Date of 1st reported } \\
\text { case }\end{array}$} & \multicolumn{3}{|l|}{ Estimate duration } \\
\hline & & start date & end date & Number of days \\
\hline National & $27^{\text {th }}$ of February, 2020 & $16^{\text {th }}$ of March 2020 & \multirow{7}{*}{$\begin{array}{l}27^{\text {th }} \text { of May, } \\
2020\end{array}$} & 73 \\
\hline $\begin{array}{l}\text { North } \\
\text { central }\end{array}$ & $22^{\text {nd }}$ of March 2020 & $22^{\text {nd }}$ of March 2020 & & 67 \\
\hline Northeast & $19^{\text {th }}$ of May 2020 & $19^{\text {th }}$ of May 2020 & & 39 \\
\hline Northwest & $28^{\text {th }}$ of March 2020 & $10^{\text {th }}$ of April 2020 & & 48 \\
\hline Southeast & $27^{\text {th }}$ of March 2020 & $25^{\text {th }}$ of April 2020 & & 33 \\
\hline $\begin{array}{l}\text { South - } \\
\text { south }\end{array}$ & $23^{\text {rd }}$ of March 2020 & $5^{\text {th }}$ of May 2020 & & 53 \\
\hline Southwest & $27^{\text {th }}$ of February 2020 & $16^{\text {th }}$ of March 2020 & & 73 \\
\hline
\end{tabular}




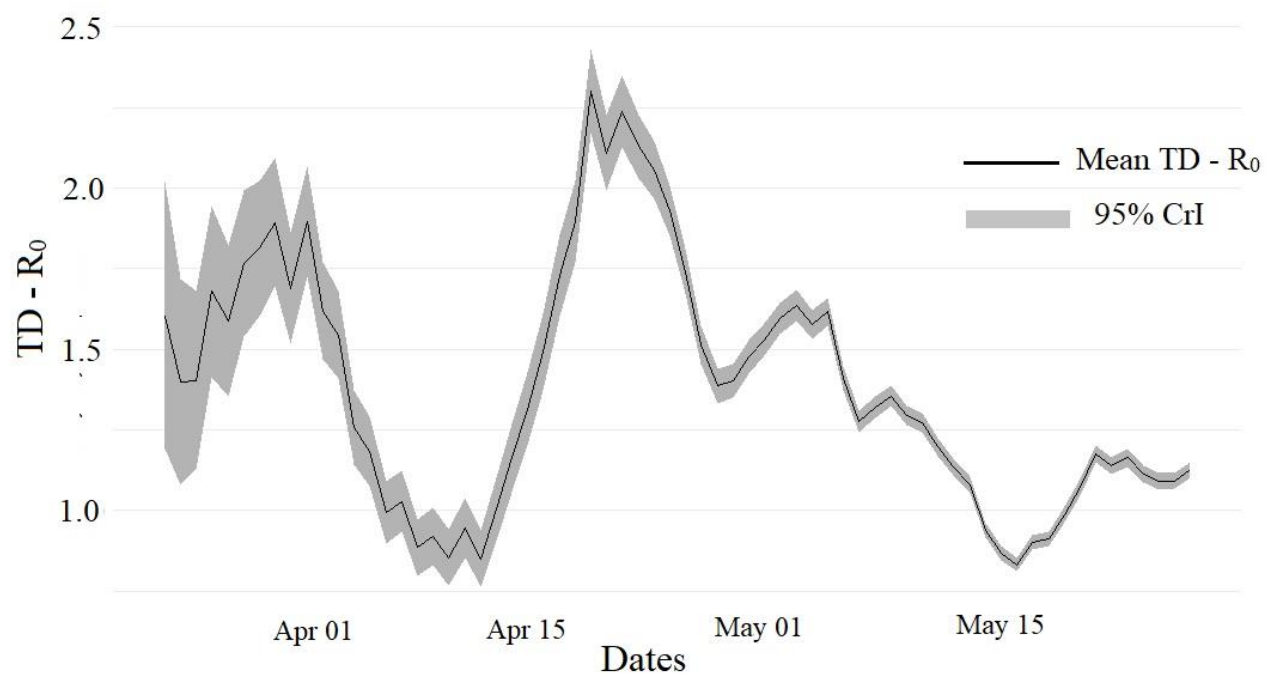

Figure 4. Estimated TD $-\mathrm{R}_{0}$ for Nigeria from $23^{\text {rd }}$ March $2020-17^{\text {th }}$ May 2020

The time series data of COVID - 19 infections in the country were used in estimating TD $-\mathrm{R}_{0}$ for the country, then repeated for each of the six geo political zones. The start date and time length of each estimate are presented in Table 2. The start date for the estimates in each area was chosen based on the consistency of reported daily cases to minimize error. The mean $\mathrm{TD}-\mathrm{R}_{0}$ for the country and the geopolitical zones were plotted against a credible interval (CrI) of 95\% (see Figures 4 and 5). There was a time interval of one week between the start date of estimate and the resulting $T D-\mathrm{R}_{0}$ based on the output configuration further explained by Thompson et al. [7]. The estimated mean TD $-\mathrm{R}_{0}$ for the country from the $23^{\text {rd }}$ of March to the $27^{\text {th }}$ of April 2020 fluctuated with a maximum of $2.30(95 \% \mathrm{CrI})$ recorded on the $19^{\text {th }}$ of April and a minimum of 0.83 (95\% CrI) recorded on the $16^{\text {th }}$ of May 2020 with an overall median of 1.34 (95\% CrI). Our estimates of $\mathrm{TD}-\mathrm{R}_{0}$ for Nigeria are lower than those obtained by
Adegboye et al [9] during the early transmission stage of COVID 19 in the country and also for the month of April. For instance, our estimated TD - R0 for the $11^{\text {th }}$ of April is 0.95 (95\% CrI) compared to their estimate of 2.71 (95\% CrI).

There are variations in the estimated $\mathrm{TD}-\mathrm{R}_{0}$ across the geo - political zones (Figure 5). The southwest has a maximum TD $-\mathrm{R}_{0}$ of $2.30(95 \% \mathrm{CrI})$ that recorded on the $19^{\text {th }}$ of April and a minimum of $0.87(95 \% \mathrm{CrI})$ on the $10^{\text {th }}$ of April 2020 and a median of 1.31. Other geo - political zones have recorded much higher maximum and lower minimum TD $-R_{0}$ than the southwest. For instance, the northwest recorded a maximum $\mathrm{TD}-\mathrm{R}_{0}$ of 3.97 $(95 \% \mathrm{CrI})$ on the $1^{\text {st }}$ of May and a minimum of 0.62 (95\% CrI) on the $24^{\text {th }}$ of May 2020. Apart from the northeast and the northwest geo - political zones TD - R0 is still above 1.0 for the country and the other four zones $(95 \% \mathrm{CrI})$ as of the $27^{\text {th }}$ of May 2020. 

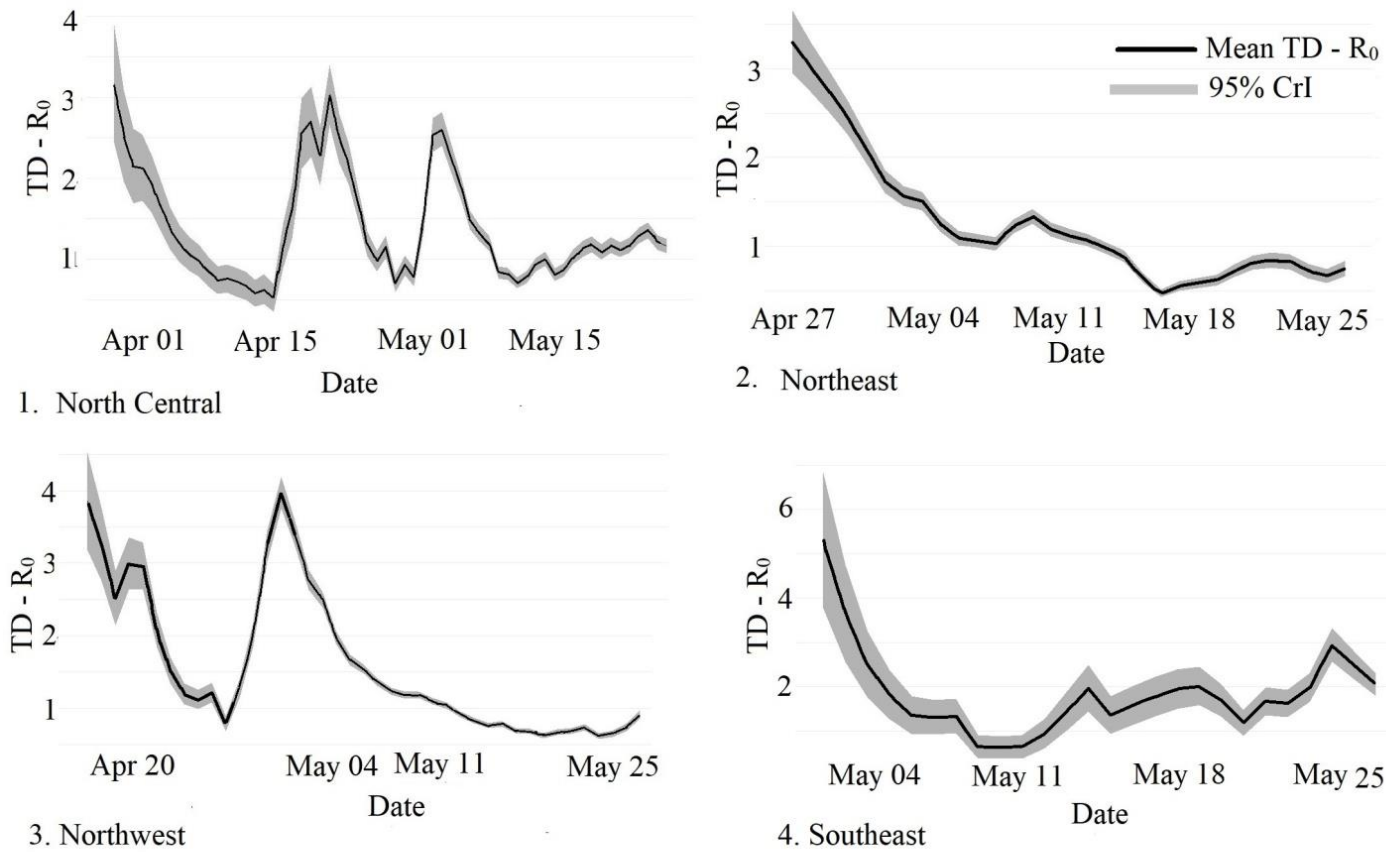

3. Northwest
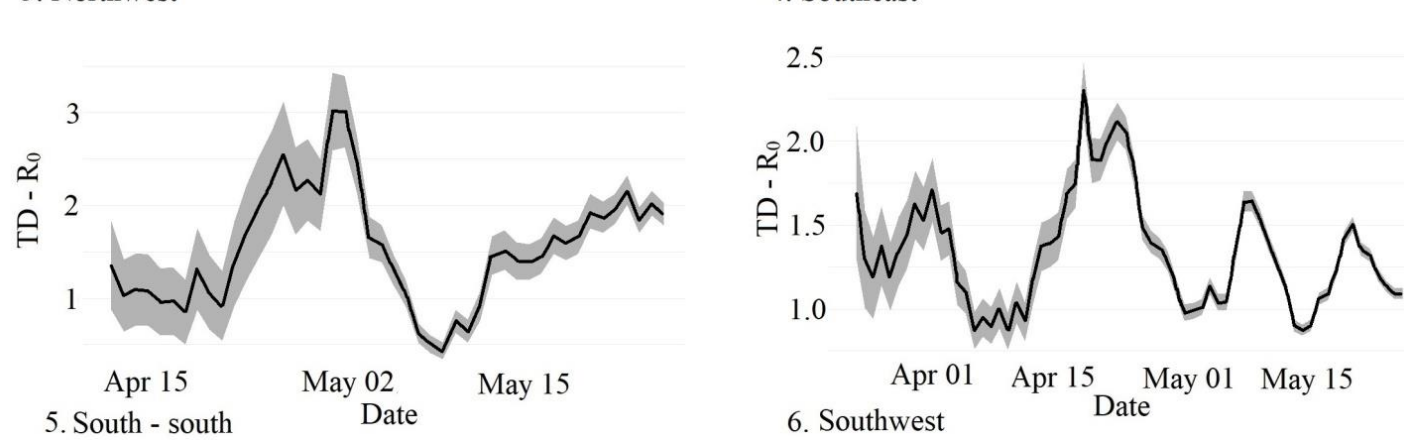

Figure 5. TD $-\mathrm{R}_{0}$ across the six geo - political zones in Nigeria

We intended to test the statistical significance of the differences in the estimated TD $-\mathrm{R}_{0}$ among the geo - political zones and also verify our null hypothesis by carrying out a pair wise KS test. The results of the KS test were adjusted for Type 1 error based on six methods and are presented in Figure 6. The null hypothesis is to be accepted if $p<0.05$. Adjusted values $\mathrm{p}<0.05$ were obtained between pair wise comparison of southeast and four other geo political zones (north central, northeast, northwest and southwest) based on all the six methods used in the Type 1 error adjustment. Our results are similar to the findings of Arruda et al. [6] on regional differences in the transmissibility of influenza in a breed of domestic animals in the United States of America. Also, adjusted value of $\mathrm{p}<0.05$ was obtained between the northeast and south - south geopolitical zones.

\section{Discussion}

Comparisons of the $\mathrm{TD}-\mathrm{R}_{0}$ curves in Figures 4 - 5 for the country and the six geo - political zones suggest a certain consistency with $\mathrm{TD}-\mathrm{R}_{0}$ fluctuating before finally decreasing apart from the south - south. Such fluctuations correspond to the implementation of certain policies by the national and the regional governments to control the spread of COVID -19 . The first response by the authorities when the number of reported cases started to increase was to restrict movement of people and encourage social distancing. This was implemented by closure of public facilities and imposing lockdowns within and outside individual states. As indicated by the curves this led to the initial drop in $\mathrm{TD}-\mathrm{R}_{0}$. In the second week of April, an effort was made to increase the number of screenings for COVID -19 across the country, and subsequently, the number of reported cases also increased. This process was slightly delayed in Kano which is the epicenter of the disease in the northwest and reflected in the TD $-\mathrm{R}_{0}$ curve for the northwest. TD $-\mathrm{R}_{0}$ is a measure of the transmissibility of a disease. Despite the decrease in transmissibility of COVID - 19 in Nigeria, there are some parts of the country like the southeast and the southwest where the level of transmissibility of the disease is high even though the number of reported 
infections are low compared to other geo-political zones. Coupled with the fluctuations in $T D-R_{0}$ many zones of the geo-political zones of the country there is need to review and strengthen its mitigation strategies for controlling COVID - 19. The review of strategies is especially necessary for some geo political zones like the southeast where the pattern of transmissibility of the disease is quite different from the rest of the country.

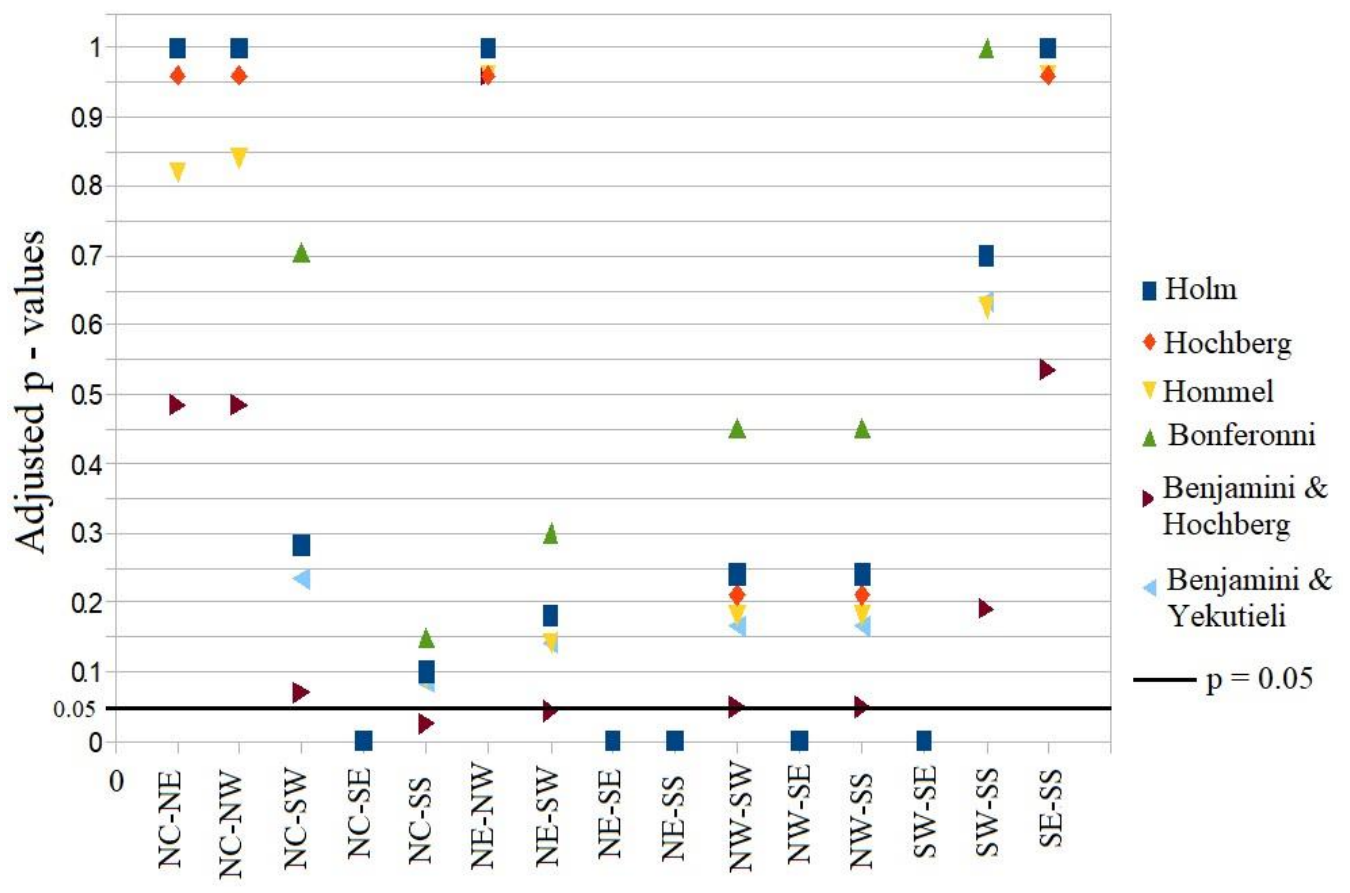

Figure 6. Results of Type 1 error adjustments of $\mathrm{p}$ - values obtained from the pair wise KS test of estimated TD $\mathrm{R}_{0}$ among geo - political zones. Type 1 error test was carried out using 6 different methods. Adjusted $\mathrm{p}$ $=0.05$ marked by the black line is the upper boundary limit for accepting the null hypothesis.

Note: null hypothesis is accepted for adjusted $\mathrm{p}<$ 0.05 based on all the six adjustment methods for Type 1 error test. This is true for at least 5 pair wise comparisons. The following abbreviations represents: NC - North central, NE - Northeast, NW Northwest, SE - Southeast, SS - South - south and SW - Southwest

\section{Conclusion}

Our findings indicate a decline in the rate of secondary infections of COVID - 19 in Nigeria as presented in the TD $-\mathrm{R}_{0}$ curves. It has also been established that such potentials for secondary infections are sensitive to control measures aimed at mitigation. Notable, of such government efforts, is the screening of more people for COVID - 19 as the credibility of this method and similar others depend on the proportion of infection incidences recorded. Nevertheless, we are able to show that a simple technique like the one that we used can be effective in studying trends in an epidemic and evaluate strategies adopted to mitigate the spread of a disease. The study was able to establish that apart from the southeast the transmissibility pattern across the geo political zones is homogeneous. Therefore, we propose the use of similar methods as the one in this paper across Africa for the study of the COVID - 19 pandemic.

\section{References}

[1] Adhikari, S.P.; Meng, S.; Wu, Y.-J.; Mao, Y.P.; Ye, R.-X.; Wang, Q.-Z.; Sun, C.; Sylvia, S.; Rozelle, S.; Raat, H.; et al. Epidemiology, causes, clinical manifestation and diagnosis, prevention and control of coronavirus disease (COVID-19) during the early outbreak period: a scoping review. Infect. Dis. Poverty 2020, 9, 29, doi:10.1186/s40249-020-00646-x.

[2] Abbas, A.M.; Fathy, S.K.; Fawzy, A.T.; Salem, A.S.; Shawky, M.S. The mutual effects of COVID-19 and obesity. Obes. Med. 2020, 19, 100250, doi:10.1016/j.obmed.2020.100250.

[3] Anderson, R.M.; Heesterbeek, H.; Klinkenberg, D.; Hollingsworth, T.D. How will countrybased mitigation measures influence the course of the COVID-19 epidemic? The Lancet 2020, 395, 931-934, doi:10.1016 /S0140-6736(20) 30567-5. 
[4] NCDC COVID-19 OUTBREAK IN NIGERIA: Situation Report; National Centre for Disease Control: Abuja, Nigeria, 2020; p. 2;.

[5] Mustapha, J.O.; Adedokun, K.A.; Abdullahi, I.N. Public health preparedness towards COVID-19 outbreak in Nigeria. Asian Pac. J. Trop. Med. 2020, doi:10.4103/19957645.279650.

[6] Arruda, A.G.; Alkhamis, M.A.; VanderWaal, K.; Morrison, R.B.; Perez, A.M. Estimation of Time-Dependent Reproduction Numbers for Porcine Reproductive and Respiratory Syndrome across Different Regions and Production Systems of the US. Front. Vet. Sci. 2017, 4, 46, doi:10.3389/fvets.2017.00046.

[7] Thompson, R.N.; Stockwin, J.E.; van Gaalen, R.D.; Polonsky, J.A.; Kamvar, Z.N.; Demarsh, P.A.; Dahlqwist, E.; Li, S.; Miguel, E.; Jombart, $\mathrm{T}$.; et al. Improved inference of time-varying reproduction numbers during infectious disease outbreaks. Epidemics 2019, 29, 100356, doi:10.1016/j.epidem.2019.100356.

[8] Musa, S.; Zhao, S.; Wang, M.; Habib, A.; Mustapha, U.; He, D. Estimation of exponential growth rate and basic reproduction number of the coronavirus disease 2019 (COVID-19) in Africa; 2020;

[9] Adegboye, A.O.; Adekunle, I.A.; Gayawan, E. Early Transmission Dynamics of Novel Coronavirus (COVID-19) in Nigeria. Int. J. Environ. Res. Public. Health 2020, 17, doi:10.3390/ijerph17093054.

[10] Adekunle, A.I.; Adegboye, O.; Gayawan, E.; McBryde, E. Is Nigeria really on top of COVID-19? Message from effective reproduction number. medRxiv 2020, 2020.05.16.20104471, doi:10.1101/2020.05.16.20104471.

[11] United Nations, Department of Economic and Social Affairs, Population Division World Population Prospects 2019, Online Edition. Rev. 1.; 2019;
[12] Campbell, F.; Strang, C.; Ferguson, N.; Cori, A.; Jombart, $\mathrm{T}$. When are pathogen genome sequences informative of transmission events? PLOS Pathog. 2018, 14, e1006885, doi:10.1371/journal.ppat.1006885.

[13] Hu, F.-C. The Estimated Time-Varying Reproduction Numbers during the Ongoing Pandemic of the Coronavirus Disease 2019 (COVID-19) in 12 Selected Countries outside China. medRxiv 2020, 2020.05.10.20097154, doi:10.1101/2020.05.10.20097154.

[14] Villabona-Arenas, C.J.; de Oliveira, J.L.; de Sousa-Capra, C.; Balarini, K.; Pereira da Fonseca, C.R.T.; Zanotto, P.M. de A. Epidemiological dynamics of an urban Dengue 4 outbreak in São Paulo, Brazil. PeerJ 2016, 4, e1892, doi:10.7717/peerj.1892.

[15] Nishiura, H.; Linton, N.M.; Akhmetzhanov, A.R. Serial interval of novel coronavirus (COVID-19) infections. Int. J. Infect. Dis. 2020, 93, 284-286, doi:10.1016 /j.ijid.2020. 02.060 .

[16] Holm, S. A Simple Sequentially Rejective Multiple Test Procedure. Scand. J. Stat. 1979, 6, 65-70.

[17] Hochberg, Y. A sharper Bonferroni procedure for multiple tests of significance. Biometrika 1988, 75, 800-802, doi:10.1093 /biomet/75. 4.800 .

[18] Hommel, G. A stagewise rejective multiple test procedure based on a modified Bonferroni test. Biometrika 1988, 75, 383-386, doi:10.1093/biomet/75.2.383.

[19] Benjamini, Y.; Hochberg, Y. Controlling the False Discovery Rate: a Practical and Powerful Approach to Multiple Testing. J. R. Stat. Soc. Ser. B Methodol. 1995, 57, 289-300.

[20] Benjamini, Y.; Yekutieli, D. The control of the false discovery rate in multiple testing under dependency. Ann Stat. 2001, 29, 1165-1188, doi:10.1214/aos/1013699998. 